\title{
HVMANITAS
}

\section{A púrpura aviltada: honra e desonra nas Vidas dos Césares de Suetónio}

\author{
Autor(es): $\quad$ Brandão, José Luís Lopes
}

Publicado por: Faculdade de Letras da Universidade de Coimbra, Instituto de Estudos

URL

persistente: URI:http://hdl.handle.net/10316.2/23019

DOI: $\quad$ DOI:http://dx.doi.org/10.14195/2183-1718_63_18

Accessed : $\quad$ 26-Apr-2023 13:34:25

A navegação consulta e descarregamento dos títulos inseridos nas Bibliotecas Digitais UC Digitalis, UC Pombalina e UC Impactum, pressupõem a aceitação plena e sem reservas dos Termos e Condições de Uso destas Bibliotecas Digitais, disponíveis em https://digitalis.uc.pt/pt-pt/termos.

Conforme exposto nos referidos Termos e Condições de Uso, o descarregamento de títulos de acesso restrito requer uma licença válida de autorização devendo o utilizador aceder ao(s) documento(s) a partir de um endereço de IP da instituição detentora da supramencionada licença.

Ao utilizador é apenas permitido o descarregamento para uso pessoal, pelo que o emprego do(s) título(s) descarregado(s) para outro fim, designadamente comercial, carece de autorização do respetivo autor ou editor da obra.

Na medida em que todas as obras da UC Digitalis se encontram protegidas pelo Código do Direito de Autor e Direitos Conexos e demais legislação aplicável, toda a cópia, parcial ou total, deste documento, nos casos em que é legalmente admitida, deverá conter ou fazer-se acompanhar por este aviso. 
humanitas

Vol. LXIII

2011 


\title{
A PÚRPURA AVILTADA: HONRA E DESONRA NAS VIDAS DOS CÉSARES DE SUETÓNIO
}

\author{
José Luís Lopes BRANDÃo \\ Universidade de Coimbra
}

\section{Resumo}

Analisamos neste estudo as ocorrências de termos semanticamente relacionados com os conceitos de honra e desonra, tendo em conta o contexto em que cada palavra ocorre. Suetónio está preocupado com a dignidade do imperador e das classes altas, pelo que, hasteado numa perspectiva moral e nos tópicos da tradição retórica, censura os comportamentos dos imperadores que implicam desrespeito pelo status do princeps e pela maiestas do povo romano.

Palavras-chave: Suetónio, biografia, História de Roma, honor, dignitas, infamia, ignominia.

\section{Abstract}

In this article we analyse the occurrences of words semantically related to the concepts of honour and dishonour, in order to consider the context in which each one occurs. Suetonius is concerned about the dignity of the emperor and of the higher classes and, by following a moral perspective and topics of the rhetorical tradition, he criticizes imperial behaviours involving disrepute to the status of the princeps and to the maiestas of the Roman people.

Keywords: Suetonius, biography, Roman history, honor, dignitas, infamia, ignominia.

Nas Vidas dos Césares de Suetónio encontramos marcas de uma sociedade baseada na honra, presentes na tradição do mos maiorum. No que 
toca ao imperador e às classes mais elevadas, há uma preocupação com a dignitas. $\mathrm{O}$ estatuto do princeps requer a nobreza familiar que possa garantir a ascensão ao trono, mas também um comportamento que permita manter a dignitas do governante e do povo romano. O biógrafo procura assinalar as qualidades de carácter ou, pelo contrário, as acções que deslustram o cargo.

O conceito de honor entre os romanos está, como é sabido, ligado à carreira, aos cargos desempenhados e aos títulos coleccionados, a concessões feitas aos súbditos ou à memória de alguém. A primeira rubrica das Vidas dos Césares versa precisamente sobre os antepassados - origem mais ou menos ilustre, as carreiras, os cargos que desempenharam e que conferem nobilitas, os actos egrégios e os menos dignos que praticaram.

A base é o culto dos antepassados e a tradição retórica. A enumeração das honras da família entronca na prática romana de conservar no átrio as imagines dos antepassados, acompanhadas dos tituli que as identificavam e enumeravam os cargos civis e militares dos ilustres representados, reunindo informações genealógicas, honoríficas e fisionómicas. Por sua vez, as laudationes funebres incluíam como tópico essencial o elogio dos antepassados do defunto tal como já acontecia no encomium grego; e, no tocante ao defunto, elencavam o seu cursus honorum e as res gestae 1 . Em suma, as rubricas habituais em Suetónio (origem familiar e antepassados, lugar de nascimento, presságios da fortuna futura, infância, a entrada na vida pública, aspectos de governação, obras públicas e jogos oferecidos, campanhas, aspectos da vida privada, cena de morte) constituíam já a base das laudationes ${ }^{2}$. Esta forma tradicional, cultivada pela retórica, parece deixar reflexo particularmente em alguns passos do biógrafo: com efeito, têm carácter laudatório a abordagem de Germânico, no início da Vida de

${ }^{1}$ Como se verifica pelo conteúdo do discurso de César em louvor da tia, transmitido por Suetónio (Jul. 6.1.), e do de Nero em louvor de Cláudio, segundo o testemunho de Tácito (Ann. 13.3.1). O autor dos Annales conta que, enquanto Nero elogiava os antepassados de Cláudio, a cultura do defunto e a segurança externa do Estado durante o seu principado, todos o escutavam com seriedade, mas quando passou a elogiar a prouidentia e a sapientia do imperador, ninguém foi capaz de conter o riso, apesar da elegância do discurso, composto por Séneca.

${ }^{2}$ Temas que aparecem também em obras como o Panegírico de Trajano, da autoria de Plínio-o-Moço, ou nas Res Gestae de Augusto, como nota Warmington 1999: ix. 
Calígula, e de Druso, no início da Vida de Cláudio, bem como a forma de começar a Vida de Tito 3 .

O discurso oposto à laudatio - a uituperatio - tinha igualmente grande tradição em Roma e incluía tópicos idênticos ${ }^{4}$. As acusações de depravação, muitas vezes sem fundamento, tradicionais no contexto da luta política republicana ${ }^{5}$, aparecem também na oposição aos imperadores ${ }^{6}$. E Suetónio aproveita, conforme os seus intuitos caracterológicos, exemplos da propaganda favorável ou desfavorável a determinado César.

A família é fonte de honra e de dignitas. No que toca a Augusto, é preocupação do biógrafo mostrar, contra as opiniões dos detractores, que a família paterna era praecipua (Aug. 1) e que a materna contava com muitos senadores e magistrados (Aug. 4.1). Galba não tem ligações directas à casa dos Césares ${ }^{7}$, embora tenha sido um protegido de Lívia, mas o peso da dinastia anterior é tal que sente necessidade de criar uma linhagem divina rival. Quando se torna imperador, expõe no átrio uma árvore genealógica que o faz remontar a Júpiter pelo lado paterno e a Pasífae, esposa de Minos, pelo lado materno ${ }^{8}$. A suspeita de que Druso seria filho do padrasto, Augusto, contribui subtilmente para aumentar a sua nobilitas $(\mathrm{Cl} .1 .1)$. Um trunfo decisivo para nobilitar a família de Vespasiano foi o casamento do pai do imperador, Flávio Sabino, com Vespásia Póla, oriunda de uma

${ }^{3}$ Como nota Lewis 1991: 3648. Vide Brandão 2009: 21-27.

${ }^{4}$ Segundo Lewis 1991: 3643-3657, Suetónio, ao descrever as carreiras pré-imperiais, parece seguir um modelo semelhante ao das laudationes e uituperationes forenses de Cícero: apresenta semelhanças com o encomium e os tratados de retórica gregos, mas tem um conteúdo e uma estrutura moldados às práticas da vida pública romana.

${ }^{5}$ Como as acusações de homossexualidade passiva e adultério, feitas a César pelos seus inimigos políticos, entre os quais Cícero (Jul. 49-52), e a Augusto, por Sexto Pompeio e António (Aug. 68-69).

${ }^{6}$ Não falta quem acuse Domiciano de ter sido iniciado sexualmente por Nerva (Dom. 1.1). Apareceram as crónicas escandalosas dos imperadores, sobretudo os anteriores a Nerva: Fânio terá escrito um De sceleribus Neronis; vide Baldwin 1983: 66-100. domum.

${ }^{7}$ Cf. Gal. 2: Neroni Galba successit nullo gradu contingens Caesarum

${ }^{8}$ Há um paralelo com a insistência de César em invocar a sua descendência de Vénus: vide Martin 1991: 80. Parece implícita na árvore genealógica de Galba uma descendência do Sol, de quem Pasífae era filha. 
família nobre (honestum genus), da antiga cepa equestre de Núrsia (Ves. $1.3)^{9}$.

Os feitos dos antepassados ilustram a estirpe, mas podem, por outro lado, dizer muito sobre o carácter dos biografados. Suetónio não regista apenas feitos ilustres da ascendência. Na Vida de Galba, refere, por exemplo, a perfidia de Sulpício Galba, governador da Hispânia que chacinou trinta mil lusitanos, provocando a guerra de Viriato, e a participação de um neto deste no cesaricídio (Gal.3.2). No início da Vida de Tibério, o biógrafo divide os Cláudios em dois grupos: Multa multorum Claudiorum egregia merita, multa etiam sequius admissa in rem p. extant («registam-se muitos feitos meritórios de muitos Cláudios, mas também muitas acções menos boas contra o Estado»), uma espécie de fundamentação das contradições de carácter do imperador ${ }^{10}$. De modo semelhante, a carga hereditária dos Domícios Aenobarbos determina o carácter de Nero, pelo que Suetónio, de modo selectivo, transmite apenas aspectos negativos da estirpe ${ }^{11}$.

Os honores que cada cidadão atinge conferem prestígio. Mas tornam-se inaceitáveis para a mentalidade romana quando ultrapassam o que é devido a um cidadão e a um homem em vida. Tal foi o erro de César, que aceitou honras desmedidas que tornavam justa a sua morte (Jul. 76.1); de Calígula, que ultrapassou o fastigium dos príncipes e dos reis, na procura de arrebatar a maiestas dos deuses (Cal. 22.1); ou de Nero, cuja notícia da aclamação vem acompanhada da nota negativa de que, na Cúria, não rejeitou nenhum dos honores, qualificados como immensi, à excepção do título de patris patriae, que recusou por causa da idade ${ }^{12}$. Domiciano mostra-se desde a juventude minime ciuilis e immodicus nas palavras e nos $\operatorname{actos}^{13}$, pelo que, depois de se tornar imperador, aceita que o apelidem de

${ }^{9} \mathrm{O}$ biógrafo regista que, na localidade que guarda o nome gentilício materno de Vespasiano, Vespasiae, subsistem complura monumenta que representam magnum indicium splendoris familiae ac uetustatis.

${ }^{10}$ Tib. 2.1. Vide Lindsay 1995: 12.

${ }^{11}$ Nero 1.2: Pluris e familia cognosci referre arbitror, quo facilius appareat ita degenerasse a suorum uirtutibus Nero, ut tamen uitia cuiusque quasi tradita et ingenita ret $<t>$ ulerit. Vide Gascou 1984: 244; Martin 1991: 74; Lounsbury 1991: 3751.

${ }^{12}$ Nero 8. Segundo Warmington 1999: 31, votaram-se em bloco todos os poderes do princeps acumulados por Augusto e desde então acrescentados; e não há razão para crer, apesar do adjectivo immensi de Suetónio, que fossem acrescentadas novas honras. Vide Lesuisse 1961: 383-390.

${ }^{13}$ Dom. 12.3: Ab iunenta minime ciuilis animi, confidens etiam et cum uerbis 
dominus et deus (Dom. 13.1-2), recebe honras exageradas (Dom. 13.2-3), ao ponto de se tornar um tirano odiado ${ }^{14}$. $\mathrm{O}$ excesso de honras torna-se, paradoxalmente, uma degradação, porque é sinal de inciuilitas e aproxima os imperadores dos tiranos orientais ${ }^{15}$. A recusa de honras torna-se, por isso, sinal de moderatio e ciuilitas $^{16}$ : tal é o procedimento creditado a Tibério (Tib. 26.1) e a Cláudio ( $C l$. 12.1) no início dos respectivos principados.

Um valor pelo qual os Romanos frequentemente lutavam e por vezes morriam $^{17}$ é representado pela dignitas, que se relaciona com o mérito pessoal e o orgulho de classe ${ }^{18}$. É um traço natural no cidadão consciente do status que possui em virtude do nascimento e dos serviços prestados ao Estado. É significativo o dito atribuído a César no contexto dos antecedentes da guerra civil: difficilius se principem ciuitatis a primo ordine in secundum quam ex secundo in nouissimum detrudi ${ }^{19}$ («mais dificilmente o expulsariam do estatuto de primeiro homem da cidade para o segundo lugar do que do segundo para o último»). Uma vez atingido determinado patamar dificilmente se aceita baixar o nível. A defesa da dignitas foi um argumento usado por César para empreender a guerra ${ }^{20}$. Na arenga às tropas, depois da passagem do Rubicão, César terá proclamado que se despojaria até do anel para satisfazer os que o ajudassem a defender a sua dignitas (Jul. 33 $)^{21}$.

Já antes, numa altura em que César, em luta com os Optimates, terá sido afastado do cargo de pretor, uma multidão se reunira espontaneamente para restabelecer a sua dignitas (Jul. 16.2.) ${ }^{22}$. Mais tarde, César ficará

tum rebus immodicus.

${ }^{14}$ Dom. 14.1: Per haec terribilis cunctis et inuisus, tandem oppressus est.

${ }^{15}$ Vide Brandão (2008) 116; 131-132.

${ }^{16}$ Vide Timonen 1993: 133-148. Segundo Jakobson \& Cotton 1985: 497-503, o acto de recusatio das honras que consubstanciam o poder imperial é um fenómeno tipicamente romano, sem paralelo nas monarquias orientais, explicado pelo passado republicano.

${ }^{17}$ Como afirma Lewis 1991: 3653 ss.

${ }^{18}$ Vide Balsdon 1960: 44-46.

${ }^{19}$ Jul. 29.1. Vide Canfora 2000: 145-146.

${ }^{20}$ Há em César um conflito entre a impudentia que outros lhe atribuem e a defesa da dignitas que ele alega. Vide Kaster 1997: 17.

${ }^{21}$ Afirmação acompanhada de gestos expressivos que fizeram gerar, entre os soldados que estavam mais longe, o boato de que ele estava a prometer a todos o censo equestre e a soma de dinheiro que permitiria suportá-lo.

${ }^{22} \mathrm{O}$ facto de César desmobilizar a manifestação valeu-lhe o agradecimento do senado e a revogação do decreto que o suspendera. 
exposto a críticas por conceder amplos honores a pessoas demasiado humildes, e a justificação que dá é que devia expressar gratidão a quem o tinha ajudado a defender a sua dignitas (Jul. 72).

O biógrafo constata que Cláudio, dadas as suas deficiências físicas, não consegue, desde a juventude, assegurar a dignitas ( $C l .3 .1 ; 5)$, o que implica um afastamento da vida pública para preservação da imagem da família imperial, embora o próprio Augusto reconhecesse que, nos assuntos graves, se manifestava a nobreza de alma (eugeneia) daquele neto de Lívia (Cl. 4.5-6). Contudo, ao redigir o retrato físico, o biógrafo reconhece que, quando Cláudio estava em repouso, «lhe não faltava auctoritas nem dignitas no aspecto» (Cl. 30). No geral, Suetónio apresenta Cláudio como uma pessoa incoerente e inapropriada para a tarefa que desempenha.

A dignitas significa também o estatuto de senador ou cavaleiro. Havia dificuldade na manutenção da riqueza que o estatuto exigia, carência que leva por vezes o imperador a intervir a favor dos arruinados, como fez Tibério ${ }^{23}$. Segundo Suetónio, Vespasiano, antes de ser imperador, chega a fazer tráfico de mulas para conseguir ter dinheiro suficiente para manter a sua dignitas, um expediente pouco apropriado para o estatuto senatorial que ele quer manter (Ves. 4.3), pelo que parece ser uma anedota posta a circular pela propaganda contrária aos Flávios.

O fundamento da dignitas encontra-se não só nos feitos dos antepassados, mas também nas acções louváveis do cidadão ${ }^{24}$, que o tornam merecedor do estatuto que possui. Vespasiano destitui senadores e cavaleiros por serem indignissimi, e deixa claro que a distinção entre as duas ordens se faz com base na dignitas, e não tanto na libertas, e acrescenta que, se um cavaleiro não deve ofender um senador, tem, no entanto, o direito de responder a uma ofensa (Ves. 9.2). Suetónio, cavaleiro e funcionário imperial, apoiará naturalmente a reforma de Adriano que entrega aos equites a administração imperial e exclui dessa tarefa os libertos ${ }^{25}$. Mas daqui se deduz também que o imperador, enquanto topo da pirâmide social, deve procurar manter a concórdia entre todas as classes de modo a consolidar a paz social ${ }^{26}$.

${ }^{23}$ Tib. 77.2. Como Tibério exigiu que os senadores comprovassem as causas da sua indigência, muitos se abstiveram de solicitar ajuda, por vergonha (pudor). Suetónio integra esta exigência no contexto da avareza de Tibério. Cf. Tac. Ann. 1.75.2.

${ }^{24}$ Vide Lewis 1991: 3653 ss.

${ }^{25}$ Vide Gascou 1984: 740.

${ }^{26}$ Vide Cizek 1977: 171-173. 
Na mira de preservar a dignidade das classes mais elevadas, Tibério, numa fase em que o poder do princeps é exercido de forma positiva (Tib. $35)^{27}$, usa de severa repressão para moralizar costumes degradados e defender a dignitas das classes senatorial e equestre, ameaçadas pela perversão sexual, pelos jogos cénicos e da arena e pelo desejo de lucro, pois os senadores deviam manter-se afastados de actividades comerciais. Dispôs que as matronas adúlteras fossem, à falta de acusador público, julgadas em conselho de família, segundo o mos maiorum (Tib. 35.1), e condenou ao desterro as matronas que, para contornar a lei, se furtavam à dignitas matronalis e se declaravam prostitutas. Suetónio indica o status em vez do nome, uma vez que reflecte aqui o interesse pela reputação moral da classe, mais que pela imoralidade de particulares ${ }^{28}$. Tibério desterrou ainda os jovens das classes senatorial e equestre que, para não serem impedidos de tomar parte nos jogos teatrais e da arena, se expunham voluntariamente a uma pena de infamia, que os libertava das restrições impostas à conduta da classe $^{29}$. Além disso, retirou o laticlavo a um senador que, dias antes das calendas de Julho (data em que se faziam os contratos de arrendamento urbano), se retirou para o campo, para depois daquela data poder arrendar uma casa na cidade a um preço mais baixo; exonerou do cargo de questor a um senador que casara na véspera do sorteio das províncias e se divorciou no dia seguinte (talvez porque, tendo-lhe calhado em sorte um província rica, já não necessitava do dinheiro da esposa: o que tornava patente que casara com ela por interesses materiais e não cívicos) (Tib. 35.2) - a dignidade de senador não se coadunava com este tipo de expedientes.

O imperador devia esforçar-se por, sem se tornar arrogante, conservar a dignitas inerente à sua função. Apesar de a toada dos gracejos de Vespasiano não ser negativa, Suetónio sugere que ele por vezes descia a um nível pouco compatível com o seu status ${ }^{30}$. Já o filho deste, Tito, trata

${ }^{27}$ Tib. 33: Paulatim principem exeruit praestititque etsi uarium diu, commodiorem tamen saepius et ad utilitates publicas proniorem.

${ }^{28}$ Segundo Tácito, trata-se, no primeiro caso, de Apuleia Varila (Ann. 2.50), e, no segundo, de Vistília (Ann. 2.85.2-3). Vide Lindsay 1995: 126-127.

${ }^{29}$ Augusto tinha proibido os senadores, e seus descendentes, de participarem em combates de gladiadores (cf. Aug. 43.3; Díon Cássio 48.43.3; 54.2.5), mas houve algumas excepções posteriores. Em 19, o chamado Senatus Consultum de Larino apresenta medidas contra a participação de membros das classes altas em jogos cénicos ou da arena. Vide Levick 1983: 97-115.

${ }^{30}$ Ves. 22: (...) erat enim dicacitatis plurimae, etsi scurrilis et sordidae, ut ne 
o povo com comitas, enquanto assiste aos jogos, sem contudo perder quer a maiestas quer a aequitas ${ }^{31}$. Augusto mostra-se cioso da maiestas da sua pessoa e da sua casa no trato com os soldados (Aug. 25.1) e esforça-se para que a monumentalidade da cidade iguale a maiestas do Império (Aug. 28.3). Totalmente desajustado é o comportamento de Vitélio, cuja comitas, associada ao seu facilis ac prodigus animus, o faz descer a um nível demasiado vil, no desejo de se mostrar familiar com os soldados ${ }^{32}$, pelo que o seu comportamento, quando imperador, está mais de acordo com o modo de vida anterior do que com a imperii maiestas, como observa o biógrafo (Vit. 10.1). Equanto a Cláudio, o anseio de se mostrar popular (communior aut remissior) leva-o a ter gestos e palavras pouco dignas e ao invés do seu estatuto, provocando mesmo a hilaridade dos espectadores, ao tratá-los por domini ${ }^{33}$.

Quando é o próprio imperador a cometer actos indignos, a desonra recai sobre os próprios e sobre o Estado. Se verificarmos a ocorrência em Suetónio de vocábulos como probrum, flagitium, dedecus, impudicitia, opprobrium, infamia, ignominia, e se analisarmos o contexto em que aparecem, constatamos uma preocupação com a desonra individual e colectiva. Como a biografia de Suetónio se centra quase exclusivamente na pessoa do biografado, ao ponto de omitir personagens importantes, estas expressões aparecem frequentemente ligadas ao detentor do poder supremo, como meio de caracterização.

Quanto aos actos desonrosos para os imperadores, Suetónio cataloga-os como probra, flagitia, impudicitia, designações que lançam à partida

praetextatis quidem uerbis abstineret. Segundo o biógrafo, faltava inicialmente a Vespasiano a auctoritas e a maiestas (Ves. 7.2).

31 Tit. 8.2: Populum in primis uniuersorum tanta per omnis occasiones comitate tractauit.... uerum maiestate salua nec minus aequitate.

${ }^{32}$ Vit. 7.3: tota uia caligatorum quoque militum obuios exosculans perque stabula ac deuersoria mulionibus ac uiatoribus praeter modum comis, ut mane singulos 'iamne iantassent' sciscitaretur seque fecisse ructu quoque ostenderet.

${ }^{33} \mathrm{Cl}$. 21.5: ac saepe hortando rogandoque ad hilaritatem homines prouocaret, 'dominos' identidem appellans. Indigna é também a sua reacção contra os naumachiarii que se recusam a combater: desata a correr, com um disforme coxear, a ameaçá-los e a exortá-los ao combate (Cl. 21.6). Segundo Guastella 1999: 33-44, Suetónio recria na Vida de Cláudio situações da palliata ou do mimo, e a figura deste imperador, enquanto presa de mulheres e de libertos, encarna as personagens cómicas destinadas a serem enganadas, como é o caso do senex, com um resultado que vai além do cómico - porque se trata do senhor do mundo. 
um juízo de valor sobre as acções que abarcam. O governo de Nero é marcado por diversas e reiteradas desonras - probra $(19.2 ; 39.1)$, flagitia (Nero 36.2) - que fustigam o principado, a par de desastres naturais e militares (Nero 39.1). O biógrafo divide esta Vida precisamente entre acções boas ou neutras, por um lado, e probra ac scelera, por outro (Nero 19.3). No que aos probra se refere parecem contar-se as tendências histriónicas, largamente desenvolvidas ao longo desta Vida (sobretudo Nero 20-25). O facto de o imperador se tornar actor constituía, para a mentalidade romana, não só degradação social, mas também moral. Vitélio na corte dos Júlio-Cláudios é contaminado com todo o tipo de infâmias (probra) (Vit. 4) e é assimilado aos vícios de Calígula, Cláudio e Nero. Os flagitia e dedecora de Messalina afectam negativamente Cláudio ( $\mathrm{Cl}$. 27.2), caracterizado como um ingénuo, dominado por mulheres e libertos.

O efeito é a desonra, expressa em termos como dedecus e oprobrium, e a perda do bom nome e da reputação, sugeridos por ignominia e infamia. Entre os condenados de uma conjura contra Nero, diz o biógrafo, o feito é considerado heróico e justo: Nonnulli etiam imputarent, tamquam 'aliter illi non possent nisi morte succurrere dedecorato flagitiis omnibus' («não faltava quem considerasse o acto meritório, como se 'lhe não pudessem prestar outro socorro senão com a morte a quem como ele estava desonrado por todos os actos vergonhosos'»), numa provável alusão, pelo paralelo com outras fontes, ao efeito das actividades histriónicas deste imperador ${ }^{34}$. A negligência de Tibério, recolhido na ilha de Cápreas, dá azo, no dizer exagerado de Suetónio, a que vários povos devastem as províncias, com grande desonra (dedecus) para o império ${ }^{35}$. A recusa do título de Pai da Pátria por parte de Tibério é interpretada posteriormente, à luz da evolução tirânica que as fontes dão a este principado, como forma de o próprio, conhecedor do seu carácter, prevenir a desonra (dedecus) a que seria votado se se viesse a verificar que tinha recebido indignamente tal distinção ${ }^{36}$.

${ }^{34}$ Nero 36.2. Ao dizer nonnulli etiam imputarent, Suetónio estará, como habitualmente, a generalizar: aquelas palavras, segundo Tácito, Ann. 15.68.1, foram pronunciadas somente por Sulpício Áspero. Díon Cássio (62.24.2) diz que outro conjurado, Súbrio Flávio, acrescenta que não podia ser escravo de um citaredo e de um auriga.

${ }^{35}$ Tib. 41. A negligência em relação às incursões dos Partos, que ocupam a Arménia, dos Dácios e dos Sármatas, que devastam Mésia, e dos Germanos, que invadem as Gálias, parece ser uma calúnia, se fizermos o confronto com o relato de Tácito, Ann. 6.31-44. Vide Lindsay 1995: 138.

${ }^{36}$ Tib. 67.2: ne mox maiore dedecore impar tantis honoribus inueniretur. 
Muitos dos escândalos não passam de rumores, como os que circulavam acerca da actuação "desonrosa" de Calígula na expedição à Germânia (tantorum dedecorum rumores) (Cal. 48.2), mas na análise caracterológica de Suetónio os boatos são colocados a par de factos comprovados ${ }^{37}$.

Na luta política, a esfera sexual era particularmente visada: entre os comportamentos que geravam opprobium e dedecus eram particularmente gravosos os actos de impudicitia, termo que em Suetónio é sinónimo de práticas homossexuais passivas, desonrosas para o cidadão livre. A notícia de que César, na juventude, partilhou o leito de Nicomedes da Bitínia, é apresentada como um rumor (Jul. 2), mas foi tal efeito sobre a fama da sua pudicitia, que constituiu um opprobrium para o resto da vida (Jul. 49.1), uma vez que o deixava exposto às críticas dos opositores políticos ${ }^{38}$. Também Calígula e Nero, conotados com os topoi da tirania, não poupam a pudicitia (Cal. 36.1; Nero 29.1). O próprio Augusto fora marcado desde a juventude com a suspeita de actos desonrosos (dedecora) do mesmo género (Aug. 68), mas facilmente refutou a acusação de impudicitia com a castitas da vida (Aug. 71.1.); ele próprio, no que respeita à punição da filha, dizia preferir a morte dos seus à desonra (dedecus $)^{39}$. Claro que o processo de construção da personagem de Augusto é ao contrário dos tiranos: os vícios são relegados para a juventude de modo a deixar prevalecer no final uma imagem favorável.

Numa sociedade que cultiva a honra, a manutenção do bom nome é naturalmente uma preocupação constante. Daí decorre que penas de infamia ou ingnominia poderiam ser decretadas pelos senatusconsulta, pelas notae dos censores, pelos edicta dos pretores ou pelas leges dos imperadores. Suetónio emprega o termo ignominia sobretudo numa acepção próxima de atimia $^{40}$, porquanto implica a perda de direitos civis ou abaixamento de

${ }^{37}$ Vide Brandão 2002: 331-339.

${ }^{38}$ António chama Thurinus a Augusto como se fosse um ultraje (opprobrium) (Aug. 7.1) - na verdade, tratava-se do seu cognomen primitivo, em virtude do lugar de origem dos antepassados. E Augusto alardeia ciuilitas ao classificar o tratamento por dominus como um opprobrium feito à sua pessoa (Aug. 53.1).

${ }^{39}$ Aug. 65.2: Aliquando autem patientius mortem quam dedecora suorum tulit. Nam C. Lucique casu non adeo fractus, de filia absens ac libello per quaestorem recitato notum senatui fecit abstinuitque congressu hominum diu prae pudore, etiam de necanda deliberauit. Certe cum sub idem tempus una ex consciis liberta Phoebe suspendio uitam finisset, 'maluisse se' ait 'Phoebes patrem fuisse'.

${ }^{40}$ Sobre o conceito de atimia e os direitos cuja perda esta pena acarretava 
estatuto de classe, várias formas de despromoção e desqualificação ${ }^{41}$. Ignominia significa a privação do bom nome; a desonra em resultado de uma punição militar ou civil. A maior parte das ocorrências do termo refere-se, pois, a uma ferramenta usada frequentemente pelos imperadores na sua função censória, para correcção de costumes ou da disciplina. Cum ignominia é o modo como César faz a desmobilização de uma legião que se revoltou (Jul. 69); e, de forma semelhante, Augusto (Aug. 24.2), que, inclusive, inventa outras penas desonrosas; é um instrumento usado por Augusto para punir as culpas de cavaleiros (ignominia notauit) (Aug. 39) ${ }^{42}$ e a licenciosidade de um certo Céstio Galo (Tib. 42.2). A ignominia representa a desonra que acompanha a demissão de um legado laxista de uma legião (ignominia notato) por parte de Tibério que, na imposição da disciplina militar, restaurou mesmo ignominiae do passado (Tib. 19.1), e representa também a desonra do afastamento dos comandantes retardatários das tropas auxiliares por parte de Calígula, quando se tratava de restabelecer a disciplina do exército da Germânia (Cal. 44.1). Domiciano, na sua actividade de censor, marca com a ignominia os autores de scripta famosa (Dom. 8.3). Para evitar a uexatio e ignominia muitos dos citados a juízo por Tibério suicidavam-se (Tib. 61.4). À parte alguns excessos, Suetónio aprova geralmente estas medidas, pois têm em vista a manutenção da dignidade das classes. Soa a afrouxamento da disciplina quando Vitélio retira as notas de ignominia no exército (Vit. 8.1).

Mas ignominia, em sentido lato, é por vezes referida aos protagonistas das Vidas: designa o estado de persona non grata, camuflado com o cargo de legado, que Tibério suportava em Rodes, onde se tinha auto-exilado durante o principado de Augusto (Tib. 12.1); bem como a suposta humilhação de Cláudio no principado de Calígula, por ser o último a intervir no senado ${ }^{43}(\mathrm{Cl}$. 9.2). Como ignominia é entendido também o resultado de

para homens e mulheres que nela incorriam na Grécia dos séculos VI e V a.C., vide Leão 2005: 61-63.

${ }^{41}$ Tornam-se ignominiosi os condenados por alguns tipos de crimes, segundo as Institutiones de Gaio (4.182). Sobre as implicações jurídicas e civis de atimia e infamia no início do Império, vide Levick 1983: 108 ss.

${ }^{42}$ Cf. Cal. 16.2. Já Cláudio, no exercício (irregular, segundo Suetónio) da censura, não impôs ignominia a um jovem licencioso, quando fazia a recognitio dos cavaleiros $(C l .16 .1)$.

${ }^{43}$ Não se trata propriamente de humilhação: segundo Díon Cássio (59.8.6), Calígula determinara em 37 que os ex-cônsules intervinham pela ordem em que 
derrotas vergonhosas para o Estado romano, como a de Lólio na Gália e a de Varo na floresta de Teutoburgo (Aug. 23.1) ${ }^{44}$; a notícia de que, no principado de Nero, as legiões terão passado sob o jugo na Arménia e de que só a custo se conseguiu manter o controlo da Síria (Nero 39.1 ${ }^{45}$ e derrotas militares nas lutas civis de 69 d.C. (Otho 9.3; Ves. 8.2).

No que respeita à ideia de má reputação ganha pelos imperadores, usa Suetónio as mais das vezes um termo afim: infamia - conceito juridicamente associado à perda de direitos reservados às classes superiores. Aparece em Suetónio frequentemente acompanhado de designações de vícios e denota o papel censor de terceiros ou da uox populi, do biógrafo ou das suas fontes. Trata-se da má fama que os príncipes adquiriram em consequência de actos indignos, verdadeiros ou suspeitados. Como infamia é classificada a suposição de que César aspirava ao título de rei (Jul. 79.2), ambição que o levará à morte; mas também o resultado da sua impudicitia e dos adultérios (Jul. 52.3). De modo semelhante, infamia é o efeito de actos desonrosos (dedecora $)^{46}$ da juventude de Augusto, sobretudo alegados favores sexuais (Aug. 68) - a infamia impudicitiae, como precisa o biógrafo mais à frente (Aug. 71.1); e dos rumores da prostituição de Domiciano na adolescência a Nerva (Dom. 1.1). Como infamia são classificadas as torpezas sexuais de Tibério em Cápreas: os abomináveis actos deste imperador no segredo da ilha são apresentados como incríveis até de conceber $^{47}$, resultantes por certo da calúnia, mas que têm um efeito devastador. Tibério é mais tarde apresentado como um conhecedor da sua infamia futura (Tib. 67.2). A infamia de Cláudio, já antes de chegar ao poder, estava ligada à ebriedade e ao jogo dos dados ( $C l$. 5.1), que serão vícios marcantes deste imperador, retomados mais à frente $(\mathrm{Cl} .33 ; 40.1)$; a de Nero estava vinculada às

tinham exercido o cargo. Cláudio, tendo sido o último, falava naturalmente em último lugar. Vide Guastella 1999: 150.

${ }^{44} \mathrm{~A}$ derrota de Lólio na Gália é conotada mais com infamia do que perda real (Aug. 23.1). Já o desastre de Teutoburgo provoca em Augusto reacções dramáticas: Adeo denique consternatum ferunt, ut per continuos menses barba capilloque summisso caput interdum foribus illideret uociferans: 'Quintili Vare, legiones redde!' diemque cladis quotannis maestum habuerit ac lugubrem (Aug. 23.2).

${ }^{45}$ A passagem sob o jugo foi apenas um rumor segundo Tácito (Ann. 15.15.2); e não é verdade que o controlo da Síria estivesse em risco.

${ }^{46}$ Aug. 68.1: Prima iunenta uariorum dedecorum infamiam subiit.

${ }^{47}$ Tib. 44.1: Maiore adhuc ac turpiore infamia flagrauit, uix referri audiriue, nedum credi fas sit. 
acusações patentes nos grafitos e escritos dos detractores sobre as mortes de Agripina e de Cláudio, a paixão do imperador pelo canto, a extravagância da Domus Aurea e a constante ameaça em que viviam os senadores, ofensas que ele não perseguiu para não agravar as críticas (Nero 39.3). Já a infamia de Vespasiano prende-se com o vício da avareza (Ves. 19.1-2), uma reputação antiga que, embora imerecida para o biógrafo, se mostrava enraizada ${ }^{48}$.

Em suma, as noções de honra e dignidade estavam tradicionalmente ligadas à consciência da cidadania e ao orgulho de uma certa aristocracia, no seio da qual Suetónio se integra, como cavaleiro, e colige as suas fontes. A desonra resulta em grande parte do carácter e tem reflexos sobre o povo romano. O vocabulário usado por Suetónio ${ }^{49}$ põe em relevo os juízos morais do biógrafo - a infamia relaciona-se sobretudo com os vícios principais. Não parece comprovar-se a tese, por vezes repetida acriticamente, de que Suetónio é unicamente descritivo e se abstém de julgar ou de tirar lições de moral, pelo que deixa essa tarefa ao leitor. ${ }^{50}$ As classificações dos actos segundo categorias atrás mencionadas, a manipulação que opera nos dados históricos, em função de determinados valores, vícios ou virtudes, denunciam uma intenção de condicionar e atrair o leitor para uma mensagem moral ${ }^{51}$. Está naturalmente

${ }^{48}$ Ves. 19.1: Et tamen nec sic quidem pristina cupiditatis infamia caruit. Ao salientar a adversativa (Et tamen nec sic quidem) e ao classificar a cupiditatis infamia de pristina, Suetónio separa a actuação presente da anterior, Vespasiano da sua fama. Segundo Cesa 2000: 86, a impressão que fica no leitor é negativa pela disposição do tema no interior da biografia. Mas, neste caso, a posição na biografia serve o fito de provar que o vício já não existe e de que a infamia é injusta. Como nota Gascou 1984: 702-703, Suetónio renuncia a deixar falar os factos, mas interpreta-os e decide, de modo arbitrário e parcial, que uns são do domínio da aparência e outros da realidade.

${ }^{49}$ Faltaria também analisar as várias referâncias às mulheres cujo pudor e infamia está limitado à esfera sexual, de acordo com o que constata também Kaster 1997: 9-10. Será o caso dos flagitia e dedecora de Messalina, esposa de Cláudio.

${ }^{50}$ Como sugerem Ailloud 1931-1932: xxiii, n. 4, na introdução à sua edição (contra os que acusam Suetónio de imoralidade, considera-o antes "amoral") e xxxii; Townend 1967: 92-93; Ektor 1980: 48 317-326.

${ }^{51}$ Vide Lewis 1991:3653: «It is sometimes argued that Suetonius is by contrast purely descriptive or 'objective', confining himself to recording information as he finds it and leaving it to the reader to make moral judgements... he does manipulate his 'plan factual data' against a known background of established values and prejudices». Vide também Bradley 1978: 14-15. 
presente uma componente retórica, pelo que alguns imperadores são vítimas dos topoi de caracterização dos tiranos ${ }^{52}$.

\section{Bibliografia:}

Ailloud, H. (1931-1932), Suétone. Vie des douze Césars, texte établi et traduit, vol. I-III. Paris, Les Belles-Lettres.

Baldwin, B. (1983), Suetonius. Amsterdam, Hakkert.

BALSDOn, J. P. V. D. (1960), “Auctoritas, dignitas, Otium”, $C Q$ N.Ser. 10 43-50.

Bradley, K. R. (1978), Suetonius' Life of Nero. An historical commentary. Bruxelles, Latomus.

Brandão, J. L. (2002), "Rumores e escândalos nas Vidas dos Césares de Suetónio" in Nascimento, A. A. (coord.) De Augusto a Adriano. Actas de Colóquio de Literatura Latina (Lisboa 2000. Novembro 29-30).

Lisboa, Centro de Estudos Clássicos/Faculdade de Letras, 331-339.

Brandão, J. L. (2008), “Tirano ao Tibre! Estereótipos de tirania nas Vidas dos Césares de Suetónio", Humanitas 60 115-137.

BRandão, J. L. (2009), Máscaras dos Césares. Teatro e moralidade nas Vidas Suetoninas. Coimbra, CECH - Classica Digitalia.

Canfora, L. (2000), Giulio Cesare. Il dittatore democratico. Roma/Bari, Laterza ( $5^{\text {a }}$ ed.).

Cesa, M. (2000), Svetonio. Vita di Vespasiano. Bologna, Cappelli.

Cizer, E. (1977), Structure et idéologie dans les Vies des douze Césars de Suétone. Paris, Les Belles Lettres.

EктоR, J. (1980), “L'impassibilité et l'objectivité de Suétone”, LEC 48 317-326.

Gascou J. (1984), Suétone historien. Paris, de Boccard.

Guastella, G. (1992), Gaio Svetonio Tranquillo, La vita di Caligola, testo, trad. e comm. Roma, La Nuova Italia Scientifica.

Guastella, G. (1999), Gaio Svetonio Tranquillo. L'imperatore Claudio. Venezia, Marsilio.

HuRley, D. W. (1993), An historical and historiographical commentary on Suetonius'Life of C. Caligula. Atlanta, Scholars Pr.

52 Vide Brandão 2008 115-137. 
JAKoBson, A. \& Cotton, H. M. (1985), "Caligula's recusatio imperii", Zeitschrift für Alte Geschichte 34 497-503.

Kaster, R. A (1997), "The shame of the Romans", APhA 127 1-19.

LEÃo, D. F. (2005), "Cidadania e exclusão: mecanismos de gradação identitária", in M. do Céu Fialho, M. de Fátima Sousa e Silva \& M. H. Rocha Pereira (coords.), Génese e consolidação da ideia de Europa. Vol. I De Homero ao fim da Época Clássica. Coimbra, Imprensa da Universidade de Coimbra, 43-75.

Lesuisse, L. (1961), "Suétone et l'aspect juridique de l'avènement de Néron", LEC 29 383-390.

Levick, B. (1983), "The Senatus Consultum from Larinum”, JRS 73 97115.

Levick, B. (1999), Vespasian. London / New York, Routledge.

Lewis, R. G. (1991), "Suetonius' Caesares and their literary antecedents", ANRW II, 33,5 3623-3674.

Lindsay, H. (1995), Suetonius, Tiberius. Ed. with intr., com. and Bibliography. London, Bristol Classical Press.

Lounsbury, R. C. (1991), "Inter quos et Sporus erat: The making of Suetonius' Nero", ANRW II, 33,5, 3748-3779.

Martin, R. (1991), Les douze Césars: du mythe à la réalité. Paris, Les Belles Lettres.

Southern, P. (1998), Augustus. London / New York, Routledge.

Timonen, A. (1993), "Emperors ars recusandi in biographical narrative", Arctos 27 133-148.

Townend, G. B. (1967), "Suetonius and his influence" in Latin biography ed. by Dorey, T. A. London, Routledge \& Kegan Paul, 79-111.

Wardle, D. (1994), Suetonius' Life of Caligula. A commentary. Bruxelles, Latomus.

W ARmington, B. H. (1999), Suetonius Nero, text, with intr. \& notes. Bristol Class. Pr. (2a ed.). 